the substance, so the substance was not removed. When the responses of the specialist physicians participating in our study to the osteoporosis preference criteria questionnaire were examined according to their specialty, no statistically significant difference was found between specialty branches but only significant difference was found in health system and cost subscale according to branches $(p=0.013)$. Posthoc test (LSD) was used to find out the group that made a significant difference in health system and cost sub-factor. higher scores $(p=0.034)$.

Conclusion: We developed and validated a general osteoporosis treatment questionnaire that could provide assessment of the criteria that physicians take into consideration when they decide to implement a regimen for osteoporosis. This tool could assist health care systems and pharmaceutical companies understand which parameters drive physicians' choices regarding the treatment of osteoporosis.

References:

[1] P. Makras, A. Galanos, S. Rizou, A. D. Anastasilakis, and G. P. Lyritis, "Development and validation of an osteoporosis treatment questionnaire (OSTREQ) evaluating physicians' criteria in the choice of treatment," Hormones, vol. 15, no. 3, pp. 413-422, Jul. 2016.

[2] S. Tuzun et al., "Incidence of hip fracture and prevalence of osteoporosis in Turkey: The FRACTURK study," Osteoporos. Int., vol. 23, no. 3, pp. 949-955, Mar. 2012

Disclosure of Interests: None declared

DOI: 10.1136/annrheumdis-2020-eular.4473

\section{AB1364-HPR IS ADHERENCE TO TREATMENT RELATED TO THE EFFECTIVENESS OF ANTI-TNFS IN PATIENTS WITH RHEUMATOID ARTHRITIS? - ANALYSIS OF A REAL- WORLD COHORT}

P. Osorio $^{1}$, L. Villarreal ${ }^{1}$, M. Cabrera ${ }^{2}$, O. Valencia ${ }^{2}$, P. Santos-Moreno ${ }^{3}$.

${ }^{1}$ Biomab - Center for Rheumatoid Arthritis, Psychology, Bogota, Colombia;

${ }^{2}$ Biomab - Center for Rheumatoid Arthritis, Data Administration, Bogota,

Colombia; ${ }^{3}$ Biomab - Center for Rheumatoid Arthritis, Rheumatology, Bogota, Colombia

Background: Several medicines are prescribed for chronic disease management of rheumatoid arthritis (RA) including biologics; however, adherence to long-term therapy remains poor because many causes; the latter results in worsening clinical results.

Objectives: To analyze the relationship between adherence to treatment and the achievement of remission or low disease activity in patients with RA treated with three anti-TNF molecules of subcutaneous use.

Methods: In patients treated with 3 subcutaneous anti-TNFs, with at least one year of follow-up previously, adherence was measured with Compliance Questionnaire for Rheumatology (CQR19) applied by psychologist; the CQR19 is a 19 item, self-administered questionnaire that was developed with the aim of correctly identify rheumatology patients that were classified as "low" adherers (taking $<80 \%$ of their medication correctly) and defining as high adhesion a result greater than $80 \%$; adherence also was measured with medication possession rate (MPR) and attendance to scheduled consultations with the interdisciplinary team in each period measured. The effectiveness by DAS28, HAQ and the other measurements were made in three periods: at baseline (BL), 6 months (M6) and 12 months (M12). A Pearson correlation was made between the number of patients in remission and low disease activity by type of molecule and period, with adherence criteria.

Results: 112 patients diagnosed with RA were included, $34.8 \%(39 / 112)$ treated with adalimumab, 38.4\% (43/112) etanercept and $26.8 \%(30 / 112)$ golimumab; The results of CQR19 at BL, M6 and M12 were greater than $80 \%$, with no statistically significant differences between the three molecules. The MPR was higher than $80 \%$ in the three periods, being very similar between the three molecules, but in M12 period the difference in MPR between adalimumab $86 \%$ and golimumab $92.1 \%$ was statistically significant ( $p<0.005$ ), for etanercept it was of $90 \%$. Regarding to DAS28 and HAQ, there were no differences between the biologics analyzed; However, the highest percentage of patients with low disease activity and remission had a higher correlation with attendance to the consultations scheduled in the interdisciplinary RA care model $(r=0.78) p<0.005$ (see tables).

\begin{tabular}{lcccccc}
\hline CQR19 & \multicolumn{7}{c}{ MPR } \\
\hline & BL & M6 & M12 & BL & M6 & M12 \\
\hline ADALIMUMAB & 89,7 & 89,3 & 90,1 & 98,5 & 90,5 & 86,1 \\
ETANERCEPT & 87,4 & 89,7 & 89,7 & 97,9 & 89,6 & 90,9 \\
GOLIMUMAB & 88,2 & 87,6 & 91,5 & 97,1 & 96,1 & 92,1 \\
\hline
\end{tabular}

No statistical differences in adherence between biologics were found depending on sex, type of concomitant conventional treatment for RA or presence of comorbidities.
RELATION BETWEEN Rem/LDA AND COMPLIANCE WITH APPOINTMENTS

\begin{tabular}{lccccc}
\hline & Rem & LDA & MDA & HDA & \\
\hline ADALIMUMAB & $63 \%$ & $60 \%$ & $53 \%$ & $29 \%$ & $\mathrm{P}<0,005$ \\
ETANERCEPT & $66 \%$ & $62 \%$ & $73 \%$ & - & - \\
GOLIMUMAB & $68 \%$ & $73 \%$ & $55 \%$ & - & $\mathrm{P}<0,005$ \\
\hline
\end{tabular}

Conclusion: There seems to be a higher MPR with the monthly golimumab compared to the biweekly adalimumab and weekly etanercept; however, it does not necessarily imply greater effectiveness. Longer term studies are needed to confirm if there is better adherence and clinical results with monthly anti-TNFs than to other dosing regimens. Patients with remission and low disease activity had greater assistance to scheduled consultations with the interdisciplinary group, regardless of the type of molecule used. This study confirms the relation between adherence to medications and care model with clinical results.

Disclosure of Interests: Paola Osorio: None declared, Laura Villarreal: None declared, Michael Cabrera: None declared, Omaira Valencia: None declared, Pedro Santos-Moreno Grant/research support from: I have received research grants from Abbvie, Biopas-UCB, Janssen, Novartis, Pfizer., Speakers bureau: I have been speaker for Abbvie, Biopas-UCB, Janssen, Lilly, Novartis, Pfizer, Roche, Sanofi. DOI: 10.1136/annrheumdis-2020-eular.4779

\section{AB1365-HPR FREQUENCY OF JOINT DAMAGE IN PATIENTS WITH ULCERATIVE COLITIS}

D. Tarasova ${ }^{1}$, L. Shilova ${ }^{1}$, E. Lutaya ${ }^{1}$, E. Korenskaya ${ }^{1}$, M. Koroleva ${ }^{1}$,

A. Feoktistova ${ }^{1}{ }^{1}$ Volgograd State Medical University, Volgograd, Russian Federation

Background: Ulcerative colitis (UC) is considered as a systemic autoimmune disease with lesions of the colon mucosa. The current of UC is often accompanied by different extra-intestinal manifestations. Their frequency, according to various studies, varies widely - from 25 to $60 \%$. It is a serious problem that affects the quality of life and the effectiveness of therapy [1, 2]. Rheumatological manifestations, in particular, damage to the joints and spine, are one of the extra-intestinal manifestations and they are of particular importance. To date, the relationship between UC and joint damage has not been fully studied. These diseases can occur independently in the body or have a common autoimmune or inflammatory nature. It is believed that having common pathogenetic mechanisms of development, UC and joint damage can be different clinical forms of the same disease.

Objectives: To evaluate the frequency of clinical manifestations of joint damage in patients with ulcerative colitis.

Methods: The study was conducted at the gastroenterological Department of the Hospital №25 (Russia, Volgograd). Archived data from the case histories of 69 patients with a confirmed diagnosis of ulcerative colitis were analyzed, including 58 men (30.4\%) with an average age of 33.4 years, and 38 women (69.5\%) with an average age of 37.6 years.

Results: Among 48 patients with UC, extra-intestinal manifestations were detected in $40(41.6 \%)$ patients. A total lesion of the large intestine was found in 20 patients $(20.8 \%)$, left-sided colitis in $14(14,6 \%)$, proctosigmoiditis in 6 $(6.25 \%)$. The diagnosis was made for the first time in 4 patients $(4.16 \%), 36$ patients $(37.5 \%)$ were admitted to the hospital again due to an exacerbation of the disease. Among the extra-intestinal manifestations, joint lesions prevailed: 20 patients $(20.8 \%)$ showed clinical signs of peripheral arthritis, spondyloarthritis was detected in 8 patients $(8.3 \%)$, and 6 patients $(6.25 \%)$ had symptoms of unilateral sacroiliitis. $4(4.16 \%)$ patients were diagnosed with nodular erythema. Primary sclerosing cholangitis was detected in two patients $(2.08 \%)$.

Conclusion: The development of extra-intestinal manifestations in UC is largely determined by the course of the disease and the length of the inflammatory process in the colon. More than a third of patients with UC revealed extra-intestinal manifestations, among which the most common signs of joint damage were present, which necessitates timely diagnosis of extra-intestinal manifestations and involvement of a rheumatologist in the management of this category of patients. References:

[1] Knyazev O. V. et al. Epidemiologi of inflammatory bowel disease. Yesterdey, today, tomorrow. Eksperimental'naya i Klinicheskaya Gastroenterologiya 2017; 139 (3): 4-12 (In Russ.)

[2] Sadygova G.G. Extraintestinal manifestations of inflammatory bowel diseases: arthropathy and arthritis. Ross z gastroenterol gepatol koloproktol 2016; 26(6):101-5 (In Russ.)

Disclosure of Interests: None declared

DOI: 10.1136/annrheumdis-2020-eular.2636 